\title{
3 Research Square

\section{Effectiveness of beclometasone dipropionate and formoterol in an extrafine particle formulation for asthma therapy depending on patient smoking status: the CASPER noninterventional, observational trial}

Izabela Kuprys-Lipinska ( $\nabla$ izabela.kuprys-lipinska@umed.lodz.pl )

https://orcid.org/0000-0002-6156-143X

\section{Tomasz Debowski}

Chiesi Poland Sp z o.o.

\section{Cezary Palczynski}

Dept. of Internal Medicine, Asthma and Allergy, Medical University of Lodz

Piotr Lacwik

Dept. of Internal Medicine, Asthma and Allergy, Medical University of Lodz

Piotr Kuna

Dept. of Internal Medicine, Asthma and Allergy, Medical University of Lodz

\section{Research article}

Keywords: Asthma, Smoking, Beclometasone Dipropionate, Formoterol, Extrafine Particle Formulation

Posted Date: March 11th, 2020

DOI: https://doi.org/10.21203/rs.3.rs-16581/v1

License: (a) (i) This work is licensed under a Creative Commons Attribution 4.0 International License. Read Full License 


\section{Abstract}

Background: The goal of asthma treatment, outlined by GINA experts, is to achieve and maintain full control of the disease. One critical risk factor for poor asthma control is exposure to tobacco smoke. The purpose of this analysis isto assess the effectiveness and safety of long-term therapy with an extrafine combined aerosol formulation of beclometasone dipropionate and formoterol (BDP/F) in asthmatics for current and ex-smokers vs non-smokers.

Methods: The CASPER study was an observational, noninterventional, prospective, multicentre trial. Asthmatics currently being managed long-term with BDP/F pressurized metred-dose inhaler (pMDI) were divided based on smoking status into three groups: current smokers, ex-smokers, and non-smokers. The subjects were evaluated at 0,3 , and 6 months for symptom intensity, asthma control, frequency of exacerbations and dose of inhaled corticosteroids. Adverse drug reactions were also monitored.

Results: Out of 16,844 patients, 2833 (16.8\%) were ex-smokers and $3312(19.7 \%)$ were current smokers. At the beginning of the observation, the current smokers were the most symptomatic subgroup of patients with the greatest limitation on life activity. During long-term treatment with extrafine BDP/F-pMDI, diurnal and nocturnal asthma symptoms, rescue medication use, and limitations of activity secondary to asthma were markedly decreased in all subgroups, with a statistically significant effect in smokers and exsmokers, albeit at the end of the observation, a higher percentage of symptomatic patients remained in the groups of current smokers and ex-smokers while a lower percentage of symptomatic patients was observed among the non smokers. At the 6-month follow-up, an improvement in asthma control compared to baseline, according to GINA criteria, was reported in $77.1 \%$ of current smokers, $75.2 \%$ of exsmokers, and $75 \%$ of non-smokers, but full asthma control was more frequently achieved in non smokers $(64.0 \%$ fulfilled GINA criteria of asthma control) compared to current smokers and ex-smokers (54.9\% and $51.5 \%$, respectively). A total of 525 nonserious ADRs were reported in 422 patients (3.2\%), all of which were within expectations.

Conclusions: Combination therapy with extrafine BDP/F-pMDI is an effective therapy across a broad spectrum of asthmatics, irrespective of smoking status, albeit the overall asthma control is worse in those with a smoking history.

\section{Background}

The goal of asthma treatment, outlined by GINA (Global INitiative for Asthma) experts, is to achieve and maintain full control of the disease and to minimize future risk of exacerbations, fixed airflow limitation, and side-effects of treatment [1]. One critical risk factor for poor asthma control and its worse prognosis is exposure to tobacco smoke, which, among others, can provoke bronchospasm [2]. Patients with baseline lung dysfunction who smoke cigarettes experience a more rapid decline in $\mathrm{FEV}_{1}$ (Forced Expiratory Volume in 1 Second) [3], increased asthma symptom severity, poorer quality of life, and more frequent ad hoc medical interventions or hospitalizations secondary to asthma exacerbations [4, 5]. In addition, the 
literature has shown that this group of patients respond less favourably to inhaled corticosteroids, even when administered at high doses [6, 7].

Irrespective of these findings, habitual tobacco use is a common comorbidity among asthma patients. Epidemiological data reveal that 17 to $35 \%$ of asthmatics in the United States and Western Europe actively smoke tobacco products [8]. In Poland, available observational studies show that current smokers, exsmokers, and those with second hand exposure constitute $17.9-19.7 \%, 16.9 \%$, and $31.86 \%$ of asthmatics, respectively $[9,10]$.

Additionally, the standards for asthma treatment are contingent on the results of randomized clinical trials, in which current tobacco use, extensive pack-year histories, irreversible obstructions, or significant lung function impairment are commonly criteria for exclusion [11, 12]. The subsequent scarcity of information regarding the effectiveness of asthma treatment in patients with a prominent smoking history prevents the optimization of therapy in this subset of asthmatics.

The aerosol of beclometasone dipropionate/formoterol $(100 / 6 \mathrm{mcg})$ in a hydrofluoroalkane (HFA) Modulite ${ }^{\circledR}$ (Chiesi Farmaceutici, Parma, Italy) pressurized metred-dose inhaler (pMDI) was developed for the routine treatment of asthmatics requiring combination therapy (inhaled corticosteroid with long-acting $\beta_{2}$-agonist) due to suboptimal disease control. This pMDI platform is characterized by its extrafine aerosolization of beclometasone dipropionate and formoterol, resulting in a median mass aerodynamic diameter (MMAD) of 1.3 and $1.4 \mu \mathrm{m}$ [13], respectively, facilitating the delivery of the drug to the lower airways, where it can directly suppress the inflammation and airflow limitation inherent to asthma. When compared to other aerosols generated from a pMDI on a chloro fluoro carbon (CFC) carrier and even to powder inhalers, this modality has translated to improve the efficacy and safety of asthma therapy through numerous clinical and observational studies $[14,15]$.

The purpose of the present analysis is to evaluate the efficacy and safety of long-term therapy using an extrafine combined aerosol formulation of beclometasone dipropionate and formoterol in asthmatics who are current or ex-smokers compared with asthmatics with no history of tobacco use.

This is a post-hoc analysis of the six months CASPER observational study enrolled 16844 asthma patients, of whom 3312 (19.7\%) smoked cigarettes during the course of the study, 2833 (16.8\%) reported smoking cigarettes in the past, and 10669 (63.5\%) denied ever smoking tobacco [10]. The primary goal of the study was to assess long-term asthma control, examine the patient's opinion of the pMDI and satisfaction with the therapy, and determine the safety of the extrafine aerosol formulation of the BDP/F combination and the effect of continued training in asthmatics in a real life setting. The result showed that the long-term use of the extrafine BDP/F combination is an effective therapy for asthma. The multiple regression analysis confirmed that smoking was an important risk factor for poor asthma control (OR, $1.27 ; 95 \% \mathrm{Cl}, 1.06-1.51 ; \mathrm{P}<0.05)$ but did not limit the overall clinical response to BDP/F combination. In the current post hoc analysis we evaluated the effect of the extrafine BDP/F combination on the various clinical parameters of smokers and ex-smokers compared to non smokers. 


\section{Methods}

\section{Study design and patient characteristics}

The CASPER study was an observational, noninterventional, prospective, multicentre trial.

Outpatients diagnosed with asthma according to routine clinical practice were assessed in a real-life setting during 3 routine visits, scheduled every 3 months over a 6-month follow-up period. The inclusion criteria were as follows: age $\geq 18$ years, diagnosis of asthma established at least 12 months before enrolment, and the use of extrafine BDP/F -pMDI (Fostex®, Chiesi Farmaceutici, Italy) for a minimum of 2 weeks before enrolment. During the programme, the patients received continued training on the proper inhalation technique. The study was planned to assess the long-term asthma control and safety of an extrafine aerosol formulation of the BDP/F combination in a real-life setting in Poland. In this post hoc analysis, the efficacy and safety of extrafine BDP/F-pMDI was evaluated in accordance with the smoking status of the studied patients.

The detailed criteria for patient participation in this study, demographic characteristics of the study group, the study schedule and the evaluation tools have been described previously [3].

In brief, at each visit, the intensity of symptoms (shortness of breath and dyspnoea, chest tightness, wheezing, cough), asthma control, and asthma exacerbations during the previous year wereevaluated. The intensity of symptoms was assessed on a 4-point scale from 0 (no symptoms) to 3 (severe limitation of daily activity). Asthma control was assessed based on the 2010 GINA criteria. An acute asthma exacerbation was defined as the need for systemic glucocorticoids administered as rescue treatment, acute hospitalization, or any other emergency intervention.

The change in symptom intensity, asthma control, frequency of exacerbations, and the dose of inhaled corticosteroids at visits 2 and 3 were compared with those at visits 1 and 2, respectively. Adverse drug reactions (ADRs) were reported according to local law.

\section{Ethics regulations}

The study was conducted in accordance with the Declaration of Helsinki [16] and local regulations. The methodology of the study fully complied with the provisions of the European Clinical Trials Directive 2001/20/EC [17] dedicated to non-interventional trials. The choice of treatment was fully based on clinical needs, as per the decision of the prescribing physician, in accordance with relevant guidelines and marketing authorizations. Consequently, inclusion in the study was clearly separated from the decision to prescribe the drug, and no additional diagnostic procedures or monitoring of vital signs were performed on the patients. Patient assignment to the study group was not driven by a protocol but fell under routine clinical practice.

Polish law does not require ethical approval and written informed consent for observational noninterventional study (information confirmed by the opinion of the local ethics committee). 


\section{Statistical analysis}

Qualitative data were presented as percentages, and quantitative data were presented as the mean and standard deviation or a median and $95 \%$ confidence interval for the mean $(95 \% \mathrm{Cl})$. To evaluate statistical significance, the following tests were performed: the $\chi 2$ test of independence, Wilcoxon signed-rank test for dependent samples, McNemar's test for alterations in sample characteristics between the study visits, Kruskal-Wallis analysis of variance test for independent variables, and Spearman's rank correlation coefficient. The case-wise deletion of missing data was applied. For comparisons and tests of independence, the pairwise deletion of missing data was applied. A p-value $<0.05$ was considered statistically significant.

\section{Results}

Of the 17,230 enrolled patients, 16,844 completed the study and were included in the analysis. The data on the status of smoking were available from 16,814 . The mean follow-up period in patients who presented at all 3 visits was $176.7 \pm 15.27$ days.

\section{Demographic and anthropometric characteristics of the study population}

Of the 16,814 studied patients, 2833 (16.8\%) reported smoking cigarettes in the past, and 3312 (19.7\%) were currently smoking cigarettes at the start of the study. The majority of both ex and present smokers were males, (Table 1). In the total population the prevalence of smoking for men and women was respectively $21 \%$ vs $12.9 \%$ for current smokers and $23.2 \%$ vs $16.3 \%$ for ex-smokers. The cohort abstaining from tobacco use was younger than the current smokers, and the ex-smokers constituted the oldest group. The mean age was $43.8 \pm 16.3$ vs $47.1 \pm 14.8$ vs $51.8 \pm 14.1$ years, respectively. Significant differences between non-smokers, ex-smokers, and current smokers were observed in level of education, physical activity, and body mass index (BMI). Non-smokers were better educated, exercised more and had a lower $\operatorname{BMI}(p<0.001)$. Detailed demographic characteristics of the study groups are presented in Table 1. 
Table 1

Demographic characteristics of the study groups acc. to smoking status.

\begin{tabular}{|c|c|c|c|c|c|c|c|c|c|}
\hline \multirow{2}{*}{$\begin{array}{l}\text { Analysed trait } \\
\text { Age (years) mean } \\
\text { (SD) }\end{array}$} & \multicolumn{2}{|c|}{$\begin{array}{l}\text { Total } \\
\text { population } \\
(\mathrm{N}=16814)\end{array}$} & \multicolumn{2}{|c|}{$\begin{array}{l}\text { Current } \\
\text { smokers } \\
(\mathrm{N}=3312)\end{array}$} & \multicolumn{2}{|c|}{$\begin{array}{l}\text { Ex-smokers } \\
(n=2833)\end{array}$} & \multicolumn{2}{|c|}{$\begin{array}{l}\text { Non-smokers } \\
(n=10669)\end{array}$} & \multirow{2}{*}{$\begin{array}{l}\text { p- } \\
\text { value } \\
< \\
0.001\end{array}$} \\
\hline & 48.8 & (16.0) & 47.1 & (14.8) & 51.8 & (14.1) & 43.8 & (16.3) & \\
\hline $\begin{array}{l}\text { Gender n (\%) } \\
\text { - female } \\
\text { - male }\end{array}$ & $\begin{array}{l}8527 \\
8287\end{array}$ & $\begin{array}{l}(50.7) \\
(49.3)\end{array}$ & $\begin{array}{l}1389 \\
1923\end{array}$ & $\left.\begin{array}{l}(41.9) \\
58.1\end{array}\right)$ & $\begin{array}{l}1097 \\
1736\end{array}$ & $\begin{array}{l}(38.7) \\
61.3)\end{array}$ & $\begin{array}{l}6041 \\
4628\end{array}$ & $\begin{array}{l}(56.6) \\
(43.4)\end{array}$ & $<.001$ \\
\hline $\begin{array}{l}\text { Education n (\%) } \\
\text { - elementary } \\
\text { - } \\
\text { vocational/secondary } \\
\text { - incomplete higher } \\
\text { - higher }\end{array}$ & $\begin{array}{l}2110 \\
7614 \\
3038 \\
4052\end{array}$ & $\begin{array}{l}(12.5) \\
45.3) \\
(18.1) \\
24.1)\end{array}$ & $\begin{array}{l}480 \\
1577 \\
586 \\
669\end{array}$ & $\begin{array}{l}(14.5) \\
47.6) \\
17.7 \\
20.2)\end{array}$ & $\begin{array}{l}456 \\
1439 \\
436 \\
502\end{array}$ & $\begin{array}{l}(16.1) \\
50.8) \\
15.4) \\
17.7)\end{array}$ & $\begin{array}{l}1174 \\
4598 \\
2016 \\
2881\end{array}$ & $\begin{array}{l}(11.0) \\
43.1) \\
18.9 \\
27.0)\end{array}$ & <. \\
\hline $\begin{array}{l}\mathrm{BMI} \geq 30 \mathrm{~kg}^{*} \mathrm{~m}^{-2} \mathrm{n} \\
(\%)\end{array}$ & 2481 & (14.8) & 566 & (17.1) & 581 & (20.5) & 1334 & (12.5) & $<.001$ \\
\hline $\begin{array}{l}\text { Declared physical } \\
\text { activity } \mathrm{n}(\%)\end{array}$ & 4446 & $(26.4)$ & 735 & $(22.2)$ & 521 & (18.4) & 3190 & (29.9) & $<.001$ \\
\hline
\end{tabular}

The duration of asthma in the ex-smokers was significantly longer, with $39.5 \%$ of subjects having asthma for more than ten years compared to $30.8 \%$ of current smokers and $27.8 \%$ of non-smokers. A positive family history of asthma was reported by approximately $60 \%$ of the patients. The mean daily dose of BDP/F-pMDI administered during the study was significantly higher in the current smokers (318.9 \pm 98.2 $\propto \mathrm{g}$ vs $313.6 \pm 99.1 \propto \mathrm{g}$ and $312.9 \pm 99.2 \propto \mathrm{g}$ in ex-smokers and non-smokers, respectively). The current smokers were also the most symptomatic subgroup of patients with the greatest limitation on activity, while the non-smokers were the least symptomatic and the least limited (Fig. 1). However, in all subgroups, both daily and nocturnal symptoms as well as a limitation of activity were reported by more than $50 \%$ of the patients. The use of rescue medication and the rate of exacerbations accompanied with the lung function limitation were similar in the current smokers and ex-smokers, with both parameters being higher than those in the non-smokers. The lung function was significantly worse in current smokers and exsmokers. Detailed clinical characteristics of the studied subgroups are presented in Table 2.

At visit 1, based on the GINA criteria, $70.5 \%$ of current smokers had uncontrolled asthma, $24.6 \%$ had partly controlled asthma, and $4.9 \%$ had controlled asthma. Asthma control was significantly worse in this group compared to the other groups; however, neither the ex-smokers nor non-smokers group demonstrated a satisfactory subset of patients with good control at this point (see Table 2). 
Table 2

Baseline clinical characteristics of the study subgroups.

\begin{tabular}{|c|c|c|c|c|c|c|c|}
\hline \multirow{2}{*}{$\begin{array}{l}\text { Analysed trait } \\
\text { Asthma duration time } \mathrm{n}(\%) \\
\text { - Up to } 5 \text { years } \\
\text { - From } 5 \text { to } 10 \text { years } \\
\text { - More than } 10 \text { years }\end{array}$} & \multicolumn{2}{|c|}{$\begin{array}{l}\text { Current } \\
\text { smokers } \\
\mathrm{n}=3312 \text { (SD) }\end{array}$} & \multicolumn{2}{|c|}{$\begin{array}{l}\text { Ex-smokers } \\
n=2833 \text { (SD) }\end{array}$} & \multicolumn{2}{|c|}{$\begin{array}{l}\text { Non-smokers } \\
\mathrm{n}=10669 \\
\text { (SD) }\end{array}$} & \multirow{2}{*}{$\begin{array}{l}\mathrm{P} \text { - } \\
\text { value }\end{array}$} \\
\hline & $\begin{array}{l}1172 \\
1120 \\
1020\end{array}$ & $\begin{array}{l}(35.4) \\
33.8) \\
(30.8)\end{array}$ & $\begin{array}{l}759 \\
955 \\
1119\end{array}$ & $\begin{array}{l}(26.8) \\
(33.7) \\
39.5)\end{array}$ & $\begin{array}{l}4257 \\
3446 \\
2966\end{array}$ & $\begin{array}{l}(39.9) \\
(32.3) \\
27.8)\end{array}$ & \\
\hline Family history of asthma $\mathrm{n}(\%)$ & 1047 & 59.5 & 926 & 60.9 & 3159 & 57.2 & $\begin{array}{l}= \\
0.045\end{array}$ \\
\hline Diurnal symptoms n (\%) & 2809 & $(84.8)$ & 2326 & $(82.1)$ & 8290 & $(77.7)$ & $\begin{array}{l}< \\
0.001\end{array}$ \\
\hline Nocturnal symptoms n (\%) & 2186 & $(66.0)$ & 1703 & $(60.1)$ & 5985 & $(56.1)$ & $\begin{array}{l}< \\
0.001\end{array}$ \\
\hline Limitation of life activity $n(\%)$ & 2256 & $(68.1)$ & 1816 & $(64.1)$ & 6241 & $(58.5)$ & $\begin{array}{l}< \\
0.001\end{array}$ \\
\hline Rescue medication use $\mathrm{n}(\%)$ & 2034 & $(61.4)$ & 1748 & $(61.7)$ & 5889 & $(55.2)$ & $\begin{array}{l}< \\
0.001\end{array}$ \\
\hline $\begin{array}{l}\text { Mean daily dose of inhaled } \\
\text { corticosteroids (SD) } \propto \mathrm{g}\end{array}$ & 318,9 & $(98,2)$ & 313,6 & $(99,1)$ & 312,9 & $(99,2)$ & $\begin{array}{l}P= \\
0.014\end{array}$ \\
\hline $\begin{array}{l}\text { Asthma exacerbations in previous } \\
\text { year } \mathrm{n}(\%)\end{array}$ & 719 & $(21.7)$ & 584 & (20.6) & 1846 & (17.3) & $\begin{array}{l}<.001 \\
0.01\end{array}$ \\
\hline $\begin{array}{l}\mathrm{FEV}_{1} \% \text { of predicted value mean }(\mathrm{SD}) \\
{[\% \mathrm{n} \text { with available results] }}\end{array}$ & $\begin{array}{l}73.5 \\
{[39,} \\
5]\end{array}$ & $(12.9)$ & $\begin{array}{l}73.8 \\
{[45,} \\
4]\end{array}$ & $(13.3)$ & $\begin{array}{l}76.3 \\
{[41} \\
6]\end{array}$ & $(13.7)$ & $<.001$ \\
\hline $\begin{array}{l}\text { GINA classification n (\%) } \\
\text { - controlled asthma } \\
\text { - partially controlled asthma } \\
\text { - uncontrolled asthma }\end{array}$ & $\begin{array}{l}162 \\
815 \\
2335\end{array}$ & $\begin{array}{l}(4.9) \\
(24.6) \\
(70.5)\end{array}$ & $\begin{array}{l}198 \\
717 \\
1978\end{array}$ & $\left.\begin{array}{l}(7.0) \\
(25.3) \\
67.7\end{array}\right)$ & $\begin{array}{l}1077 \\
3105 \\
6487\end{array}$ & $\begin{array}{l}(10.1) \\
29.1 \\
60.8)\end{array}$ & $<.001$ \\
\hline
\end{tabular}

\section{Treatment response}

The percentage of patients with diurnal and nocturnal asthma symptoms, using rescue medication, and reporting limitations of activity due to asthma was markedly decreased across all subgroups by the end of the study. However, the baseline, significant differences between the current smokers, ex-smokers, and non-smokers in these parameters were retained throughout. Similar to baseline, the current smokers and ex-smokers were more symptomatic than the non-smoking patients at the conclusion of the study (Fig. 1).

The effect size of BDP/F-pMDI on asthma symptoms was calculated as the change in the average score for individual symptoms, which showed significant differences between the study subgroups, with the highest magnitude in smokers and ex-smokers and the lowest magnitude in non-smokers (Table 3 ). 
Table 3

The effect size of BDP/F-pMDI on asthma symptoms acc. to smoking status during 6 months of observation.

\begin{tabular}{|c|c|c|c|c|c|c|c|c|c|c|}
\hline \multirow[t]{2}{*}{$\begin{array}{l}\text { Symptom } \\
\text { occurring in the } \\
\text { previous week }\end{array}$} & \multicolumn{2}{|c|}{$\begin{array}{l}\text { Current } \\
\text { smokers }^{a} \\
(n=3312)\end{array}$} & \multicolumn{2}{|c|}{$\begin{array}{l}\text { Ex-smokers } \\
b \\
(n=2833)\end{array}$} & \multicolumn{2}{|c|}{$\begin{array}{l}\text { Non- } \\
\text { smokers }^{c} \\
(n=10669)\end{array}$} & \multicolumn{4}{|c|}{  } \\
\hline & $\begin{array}{l}M \\
(\mathrm{SE})\end{array}$ & $\mathrm{Me}$ & $\begin{array}{l}M \\
(S E)\end{array}$ & $\mathrm{Me}$ & $\begin{array}{l}M \\
(S E)\end{array}$ & Me & $\begin{array}{l}\text { (a) vs } \\
\text { (b) vs } \\
\text { (c) }\end{array}$ & $\begin{array}{l}\text { (a) vs } \\
\text { (b) }\end{array}$ & $\begin{array}{l}\text { (a) vs } \\
\text { (c) }\end{array}$ & $\begin{array}{l}\text { (b) vs } \\
\text { (c) }\end{array}$ \\
\hline Dyspnoea & $\begin{array}{l}-1.09 \\
(0.02)\end{array}$ & -1 & $\begin{array}{l}-1.04 \\
(0.02)\end{array}$ & -1 & $\begin{array}{l}-1.00 \\
(0.01)\end{array}$ & -1 & $\begin{array}{l}<.001 \\
0.001\end{array}$ & $\begin{array}{l}\overline{=} \\
0.258\end{array}$ & $\begin{array}{l}<.001 \\
0.001\end{array}$ & $\begin{array}{l}< \\
0.001\end{array}$ \\
\hline Wheezing & $\begin{array}{l}-1.03 \\
(0.02)\end{array}$ & -1 & $\begin{array}{l}-1.01 \\
(0.02)\end{array}$ & -1 & $\begin{array}{l}-0.96 \\
(0.01)\end{array}$ & -1 & $\begin{array}{l}< \\
0.001\end{array}$ & $\begin{array}{l}= \\
0.060\end{array}$ & $<_{0.001}$ & $\hat{0}_{0.001}$ \\
\hline Chest tightness & $\begin{array}{l}-0.95 \\
(0.02)\end{array}$ & -1 & $\begin{array}{l}-0.94 \\
(0.02)\end{array}$ & -1 & $\begin{array}{l}-0.87 \\
(0.01)\end{array}$ & -1 & $<.001$ & $\begin{array}{l}= \\
0.520\end{array}$ & $\begin{array}{l}< \\
0.001\end{array}$ & $\begin{array}{l}<.001 \\
0.00\end{array}$ \\
\hline Cough & $\begin{array}{l}-1.11 \\
(0.02)\end{array}$ & -1 & $\begin{array}{l}-1.05 \\
(0.02)\end{array}$ & -1 & $\begin{array}{l}-1.04 \\
(0.01)\end{array}$ & -1 & < & $\begin{array}{l}= \\
0.655\end{array}$ & $<.001$ & $\begin{array}{l}<.001 \\
0.001\end{array}$ \\
\hline
\end{tabular}

Overall asthma control was ameliorated in all study subgroups due to long-term therapy with BDP/F-pMDI. An improvement in asthma control at the end of the study compared to baseline (positive change in asthma control category according to the GINA recommendations) was reported in $77.1 \%$ of current smokers, $75.2 \%$ of ex-smokers, and $75 \%$ of non-smokers (Fig. 2). The percentages in the study groups did not significantly differ.

At the 6-month follow-up, full asthma control according to the GINA criteria was achieved in $54.9 \%$ of current smokers, $51.5 \%$ of ex-smokers, and $64.0 \%$ of non-smokers. The differences between study groups were statistically significant. Detailed changes in asthma control throughout the study are presented in detail in Fig. 3.

\section{Changes in the BDP/F regimen during the study observation period}

At baseline, the proportion of patients treated with the maximal dose according to SmPC of BDP/FpMDlas basic treatment ( 2 inhalations twice daily) was higher in the current smokers. In all subgroups, the proportion of patients using the maximal dose according to SmPC of BDP/F-pMDI decreased between baseline and the end of the observation period. The dosing changes reflected the improvement in asthma control assessed by physicians. At that time, a single inhaler maintenance and reliever therapy (MART) was not yet approved. After 6 months of observation, the proportion of patients treated with lower/higher doses between the subgroups (Table 3 ) and the mean dose of inhaled corticosteroids (ICS) (289.3 \pm 99.4 ; 294.1 $\pm 99.8 ; 290.4 \pm 99.5 \mu \mathrm{g}$ for the current smokers, ex-smokers, and non-smokers, respectively) did not 
differ significantly. When compared to baseline, the proportion of patients at final visit using lower doses of BDP/F-pMDIwas significantly higher (Table 4a) and the mean dose of ICS was significantly lower in all study subgroups. (Table $4 b$ )

Table 4

a. Proportion of patients using lower and higher doses of BDP/F-pMDIduring the study according to smoking status. BID - twice daily

\begin{tabular}{|c|c|c|c|c|c|c|c|c|}
\hline \multirow[b]{2}{*}{ Baseline $\mathrm{n}(\%)$} & \multirow{2}{*}{$\begin{array}{l}\begin{array}{l}\text { BDP/F-pMDI } \\
\text { dosage }\end{array} \\
1 \text { puff BID } \\
2 \text { puffs BID }\end{array}$} & \multicolumn{2}{|c|}{$\begin{array}{l}\text { Current } \\
\text { smokers } \\
(\mathrm{N}=3312)\end{array}$} & \multicolumn{2}{|c|}{$\begin{array}{l}\text { Ex-smokers } \\
(n=2833)\end{array}$} & \multicolumn{2}{|c|}{$\begin{array}{l}\text { Non-smokers } \\
(n=10669)\end{array}$} & \multirow{2}{*}{$\begin{array}{l}\text { P- } \\
\text { value } \\
p= \\
0.012\end{array}$} \\
\hline & & $\begin{array}{l}1257 \\
1843\end{array}$ & $\left(\begin{array}{l}40.5) \\
(59.5)\end{array}\right.$ & $\begin{array}{l}1153 \\
1518\end{array}$ & $\begin{array}{l}(43.2) \\
(56.8)\end{array}$ & $\begin{array}{l}4372 \\
5662\end{array}$ & $\begin{array}{l}(43.6) \\
(56.4)\end{array}$ & \\
\hline \multirow[t]{2}{*}{$\begin{array}{l}\text { Final visit } n \\
(\%)\end{array}$} & $\begin{array}{l}1 \text { puff BID } \\
2 \text { puffs BID }\end{array}$ & $\begin{array}{l}1762 \\
1422\end{array}$ & $\begin{array}{l}(55.3) \\
(44.7)\end{array}$ & $\begin{array}{l}1451 \\
1290\end{array}$ & $\begin{array}{l}(52.9) \\
(47.1)\end{array}$ & $\begin{array}{l}5590 \\
4607\end{array}$ & $\begin{array}{l}(54.8) \\
(45.2)\end{array}$ & NS \\
\hline & & \multicolumn{2}{|c|}{$p<0.001$} & \multicolumn{2}{|c|}{$p<0.001$} & \multicolumn{2}{|c|}{$p<0.001$} & \\
\hline
\end{tabular}

Table 4

b The mean daily doses of BDP/F-pMDI during the study acc. to smoking status, DD - daily dose

\begin{tabular}{|c|c|c|c|c|c|c|c|}
\hline \multirow[t]{2}{*}{ BDP/F-pMDI DD $\propto \mathrm{g} /$ day } & \multicolumn{2}{|c|}{$\begin{array}{l}\text { Current smokers } \\
(\mathrm{N}=3312)\end{array}$} & \multicolumn{2}{|c|}{$\begin{array}{l}\text { Ex-smokers } \\
(n=2833)\end{array}$} & \multicolumn{2}{|c|}{$\begin{array}{l}\text { Non-smokers } \\
(n=10669)\end{array}$} & \multirow[t]{2}{*}{ P-value } \\
\hline & DD & (SD) & DD & (SD) & DD & (SD) & \\
\hline Baseline & 318,9 & $(98,2)$ & 313,6 & $(99,1)$ & 312,9 & $(99,2)$ & $P=0.014$ \\
\hline Final visit & 289,3 & $(99,4)$ & 294,1 & $(99,8)$ & 290,4 & $(99,5)$ & NS \\
\hline P-value & \multicolumn{2}{|c|}{$P<0.001$} & \multicolumn{2}{|c|}{$P<0.001$} & \multicolumn{2}{|c|}{$P<0.001$} & \\
\hline
\end{tabular}

\section{Adverse drug reactions}

During the study, 525 ADRs were reported in 422 patients (3.2\% of the study population). ADRs were classified as related to the use of BDP/F-pMDlin 27 patients (0.2\%). All reported ADRs were considered as expected and are listed in the summary of the product characteristics of Fostex $\circledast$. There were no differences observed between the study groups in terms of quantity and severity of ADRs.

\section{Discussion}

The CASPER study demonstrated a comparable improvement in asthma control for therapy with a pMDI administering an extrafine particle aerosol containing beclometasone dipropionate/formoterol in patients with chronic bronchial asthma subdivided by smoking status (Fig. 2). Although asthmatic patients 
exposed to tobacco smoke are generally more symptomatic during long-term treatment with an extrafine BDP/F-pMDI, the diurnal and nocturnal asthma symptoms, rescue medication use, and limitation of life activity due to asthma were markedly decreased in all subgroups, and statistically even more decreased in smokers and ex-smokers. At the 6-month follow-up, un improvement in asthma control compared to baseline, according to the GINA criteria, was reported in $77.1 \%$ of current smokers, $75.2 \%$ of ex-smokers, and $75 \%$ of non-smokers. and finally the full and partial asthma control according to GINA guidelines was achieved by $89.8 \%$, of current and ex-smokers and $92.5 \%$ of non-smokers. The full asthma control was more frequently achieved in non smokers (64.0\% fulfilled GINA criteria of asthma control) compared to current smokers and ex-smokers ( $54.9 \%$ and $51.5 \%$, respectively) (Fig. 3). A considerable clinical effect was achieved in all subgroups when using a standard dose of the formulation; however, lower daily doses of extrafine BDP/F-pMDIwere adequate in a majority of patients (Table 3). Of note, a greater percentage of patients in the ex-smokers group used higher doses compared to those in the other groups, albeit this difference was not statistically significant.

Smoking is a known factor for reducing the clinical response to inhaled corticosteroids. In studies, where smoking asthmatics used inhaled corticosteroids alone $[5,6]$, there was a weaker response to the treatment, even when the medication was administered at higher doses compared to the non-smokers. The mechanism of the development of resistance to corticosteroids because of the exposure to tobacco smoke is complex and affects both pharmacodynamic and aerodynamic properties of these drugs. Cigarette smoke induces an inflammatory response in the airways by activating both Th1- and Th2dependent pathways. Inflammatory infiltration is rich in neutrophils that are not sensitive to corticosteroids. In addition, cigarette smoke causes oxidative stress that not only activates the NF-kBdependent pathway but also affects the histone deacetylase (HDAC)/histone acetyltransferase (HAT) balance via the post-translational modification of HDAC2. Another potential explanatory mechanism regarding corticosteroid resistance may be the reduced expression of glucocorticoid alpha receptor in relation to its beta counterpart, which is observed in healthy smokers as well as in smokers with asthma [18]. The strength of this effect has been shown in a study assessing the passive exposure to tobacco smoke in children of smoking women. Thus, smoking in the case of the mother can cause, through epigenetic mechanisms, a change in DNA methylation, histone modification, and miRNA expression [19]. In addition, exposure to tobacco smoke and air pollution can lead to a synergistic effect at the level of the activation of proinflammatory genes via increased methylation and decreased expression of gammainterferon (IFNY) in effector T lymphocytes and the FOXP3 transcription factor in regulatory $\mathrm{T}$ lymphocytes, which are of great importance in the development of allergic inflammation and bronchial asthma [20].

Apart from biochemical mechanisms, particle interaction and growth should be taken into account as another mechanism contributing to the reduced clinical efficacy of inhaled corticosteroid medications in smokers. Invernizzi et al [21] showed that the particle profile of the inhaled corticosteroid (ICS) is altered when the drug is delivered in the presence of tobacco smoke with a decrease in smaller particles and a concurrent increase of larger particles. The changes in aerosol particle size might modify drug deposition and influence drug efficacy. 
In order to achieve the best therapeutic effect of ICS, avoiding drug inhalation in the environmental tobacco smoke presence (a passive exposition or an inhalation short after smoking) is quite easy to achieve. However, breaking the cellular resistance is much more difficult.

It is known that adding long acting beta2 agonist (LABA) improves the clinical response to ICS in smoking patients.

The underlying cellular mechanism for breaking steroid resistance in patients who smoke tobacco and use combination therapy with ICS withLABA remains unknown. However, LABAs intensify the response to ICS at the cellular level. Eickelberg et al. [22] showed that LABAs could in vitro activate the receptor for ICS and potentiate its effects. Rüdiger et al. [23] revealed that inhalation of budesonide activated the glucocorticoid receptor in peripheral blood leukocytes within 30 minutes, and the signal declined thereafter. Formoterol inhalation also activated the glucocorticoid receptor, but not before $60 \mathrm{~min}$, maintaining a stable signal intensity up to 4 hours. When combined, the drugs activated the glucocorticoid receptor within 30 minutes to the maximal level which did not reduce within 4 hours.

Profita et al confirmed that BDP with salbutamol or formoterol enhance nuclear translocation of GR and significantly reduces the release of GMC-CSF, RANTES and IL-8 in induced sputum cells as compared with either drug alone $(p<0.0001)$. Additionally, they found that BDP increased the expression of $\beta 2$-receptor after 30 minutes of incubation and continued to increase over a time period of 4 hours.

Interesting results were also obtained in a study of smooth muscle cells of the bronchi. Both classes of drugs activated C/EBP- $a$ and the glucocorticoid receptor and inhibited proliferation. The combination of lower doses of drugs resulted in a synchronised activation of the transcription factors and an enhanced antiproliferative effect. [24].

Descalzi et al. performed their study on human bronchial fibroblasts. They observed that BDP alone has significant antiproliferative effects on lung fibroblasts treated with basic fibroblast growth factor and the combination of BDP with formoterol or salbutamol strengthen these effects [26]. Montalbano et al. investigated the effect of recombinant human IL-17A (rhIL-17A), in combination with cigarette smoke extracts (CSE) on normal human bronchial epithelial cells. They demonstrated that both IL-17A and CSE increase the degree of oxidative/nitrosative stress by STAT-1 pathway activation or by an alternative signalling pathway but BDP and formoterol treatment reduces this effect, showing an additive action when used in combination [27].

Clinical data on the effectiveness of treatment with an ICS in combination with LABA in active tobacco users with asthma is positive but limited. In a randomized, placebo-controlled, crossover study by Clearie et al. [28], sixteen non-smokers with mild asthma and fifteen smokers were administered fluticasone/salmeterol, $250 / 50 \mathrm{mcg}$, bis in die (BiD) or fluticasone, $500 \mathrm{mg}$, BiD for 2 weeks. In this study, the smokers were conferred a significantly greater benefit from combination therapy compared to fluticasone alone in terms of reducing bronchial hyperreactivity and ameliorating lung function. 
Van Schayck et al. [29] compared the effectiveness of therapy with budesonide and formoterol, 160/4.5 $\mathrm{mcg}$, in a single inhaler, concerning maintenance and reliever therapy $(2 \times 1$ or $2 \times 2$ plus on demand), in 886 smokers with asthma with a maximum history of 10 pack-year to the effectiveness of the same treatment paradigm in patients who were non-smokers. At the beginning of the study, the smokers had worse lung function and used more rescue medications. Over the course of the treatment, comparable number of asthma exacerbations and a similar average time to first exacerbation were observed in both groups, while in smokers, a better effect was achieved at higher doses in terms of maintenance therapy. Similar results were obtained by Pilcher et al. [30] who examined the data from a 24-week randomized clinical trial with a combined budesonide/formoterol pMDI for maintenance and emergency treatment compared to a traditional treatment regimen with budesonide/formoterol pMDI in maintenance treatment and salbutamol on demand. The study comprised 59 current smokers, 97 ex-smokers, and 147 nonsmokers. The effectiveness of the therapy was better in the group treated with one single inhaler than in the group treated with the traditional regimen, regardless of smoking status. There was no significant difference between the smokers and non-smokers regarding their response to the treatment.

Brusselle et al. [31] observed a cohort of patients with moderate to severe asthma (445 non-smokers and 123 smokers), using an extrafine particle beclometasone dipropionate/formoterolpMDI. The study was conducted in real-life conditions with one-year follow-up. Therapy led to a clinically and statistically significant improvement in lung function and asthma control in both groups although the baseline lung function and the degree of asthma control were worse in the smokers than in non-smokers with asthma. This study confirmed the comparable improvement in lung function and asthma control after treatment with $\mathrm{BDP} / \mathrm{FpMDI}$ in smoking vs non-smoking patients.

In 2016, Marth et al. [32] published a prospective, noninterventional study on the effectiveness of beclometasone dipropionate/formoterol pMDI therapy in asthma patients categorized by different phenotypes, including smoking status. During 12-week treatment with BDP/FpMDI smoking patients (current and past) showed significant improvement of asthma symptoms (dyspnoea, cough, chest tightness, wheezing) and asthma control, but at the end of the study the greatest percentage of patients with good asthma control was observed in non-smokers $75.2 \%$ vs $58 \%$ in smokers and $54.2 \%$ in exsmokers, similar to the CASPER study [9].

In the last two studies conducted by Brusselle et al. [31] and Marth et al. [3] as well as in the CASPER [9] study, an extrafine particle aerosol was utilized. Subsequently, all three studies demonstrated high clinical effectiveness of the ICS + LABA combination therapy in patients exposed to tobacco smoke. The high effectiveness of the therapy, in these cases, should be related both to the synergistic action of the components and the pharmacodynamic properties of the generated aerosol.

Tobacco smoke deeply penetrates the respiratory system. MMAD for cigarette smoke amounts to approximately $0,5 \mu \mathrm{m}$, indicating that particles of its aerosol reach the small airways where they exert harmful effects, hence inducing the inflammatory process. In studies on ICS administered alone, in which efficacy was compared in asthmatic non-smokers vs asthmatic current smokers, aerosols with low pulmonary deposition and a low fraction of fine particles were used (pMDI CFC). The lack of effectiveness 
of ICS in these studies in smokers with asthma could be partly the result of minimal deposition in the small airways, where the inflammatory process occurred. In the study designed by Roche et al. [33] to compare the effectiveness of small particle and standard-size-particle ICS, adjusted rates of severe exacerbations in the annual perspective were significantly lower for current/ex-smokers and non-smokers in the small-particle than in the standard-size-particle ICS cohort, with no interaction between treatment and smoking status. In contrast, for current/ex-smokers, adjusted rates of acute respiratory events were significantly lower, and adjusted odds of risk domain asthma control were significantly higher for smallparticle ICS than for standard-size-particle ICS; for non-smokers, no difference was found. In another reallife study performed by Park et al. [34], switching from ICS/LABA DPI to pMDI in the same ICS dose category was associated with decreased asthma exacerbations and improved asthma control compared at 1 year after and before the switch. These results support the concept of the preferential use of small particle aerosols in the treatment of asthma, especially in current or ex-smokers.

The CASPER study, designed to investigate long-term effectiveness of beclometasone dipropionate/formoterol pMDI in patients with chronic bronchial asthma subdivided by smoking status, was conducted following the quotidian clinical practice and the dosage was adjusted by the physicians according to individual patient needs. Our previous multivariate analysis confirmed smoking as a risk factor for poorer asthma control. Additionally, active smoking was shown not to suppress improvement in the clinical status of the studied patients, in contrast to the improper inhaler technique, older age and extensive history of asthma [10]. Even with the load of smoking, treatment with BDP/F-pMDI resulted in a substantial improvement in asthma symptoms, decreased rescue medication needs and limitation of life activity in active and ex-smokers. However, in groups with a history of smoking, a higher percentage of patients was symptomatic throughout the entire study period (Fig. 1).

Statistically, at the end of the study, ex-smokers were the most symptomatic group and the improvement in individual symptoms was statistically lower (Fig. 1 and Tabl. 3; $p<0.05$ for both phenomena). This group tended to have worse controlled asthma (the difference in overall asthma control was significant as compare to the non-smokers but was not significant to current smokers Fig. 3), although in ex-smokers the improvement in overall disease control was still found in approximately $75 \%$. Those who quit smoking are usually older with more comorbidities compared to non-smokers and even current smokers. This effect may be attributable to health problems being a strong motivator to cease smoking, as increasingly severe obstructive disease leads to a greater likelihood for permanent departure from tobacco addiction [35, 36]. Therefore, with the ex-smokers group comprising more seriously ill individuals, it is expected that their response to treatment would be incomplete. Taken together, the data presented in the current study add to the previous literature in showing that combination therapy is an effective, albeit potentially muted, therapy across a broad spectrum of asthmatics, irrespective of smoking status.

All of the aforementioned studies demonstrated a comparable response to treatment with combination ICS and LABA in patients with varying tobacco use histories. However, the CASPER project has a number of considerable advantages relative to the above mentioned studies, including the large cohort of patients enrolled, lack of limitations in regard to the intensity and length of smoking, and a comparably long 
duration of follow-up. With such a large number of patients, the study is more representative of the general population and, more importantly, is characterized by a greater power of statistical inference.

A limitation of the CASPER study was the lack of a control group, for instance, using extrafine particle ICS alone. Furthermore, this study was an observational study; therefore, the interpretation of its outcomes is subject to the inherent restrictions of this form of research. Due to the potential bias or unrecognized confounders, it is difficult to definitively conclude a cause-and-effect relationship considering the observed phenomena. Hence, the study results should be interpreted with caution. However, the large cohort and the diversity of patients observed in terms of quotidian clinical practice elevate the representativeness of the study cohort in relation to the general population.

Another limitation could be the co-existence of chronic obstructive pulmonary disease (COPD) in some asthmatic patients; however, BDP/F pMDI was a physicians's treatment decision based on their clinical judgement. BDP/F pMDI is registered in both asthma and COPD indication, so the COPD does not exclude its use. In addition, asthma is a strong factor for developing COPD, often considered more significant than smoking [37]. Patients with asthma and COPD are more symptomatic and have worse overall asthma control [1]. These individuals are treated according to the principles of asthma treatment [1]. The study protocol, however, makes it impossible to assess the incidence of Asthma and COPD overlap (ACO)because a spirometry test was performed only in patients who had medical indications during the examination, i.e., patients with more severe disease.

In epidemiological studies, the prevalence of ACO ranged between $9 \%$ and $55 \%$, depending on gender and age. The wide variation reflects the different criteria and populations used by different investigators for diagnosing asthma and COPD [1].

In conclusion, the BDP/F therapeutic regimen in the form of extrafine particle aerosols proved to be effective in achieving and maintaining long-term asthma control and safe for patients with asthma, regardless of their smoking status. The results of our study indicate that, although the overall control of asthma is muted in patients with a previous history of smoking, the clinical response to BDP/F pMDI is comparable among the asthmatics who have never smoked, have smoked in the past and were currently smoking during the observation. However, even when administering effective medication in patients with asthma who smoke tobacco, practitioners should continue efforts to promote smoking cessation, being mindful of the harmful effects of tobacco smoke on the lungs, in particular the high risk of developing COPD and cancer, as well as the increased risk of serious cardiovascular events. Notably, there is a need to train patients on the correct use of the inhaler, to check the inhalation technique on subsequent visits, and to motivate the patients to take medication on a regular basis.

\section{List Of Abbreviations}

ACO - Asthma and COPD Overlap

ADRs - Adverse drug reactions

Page $14 / 22$ 
$\mathrm{BDP} / \mathrm{F}$ - beclometasone dipropionate/formoterol

BID - bis in die, twice daily

$\mathrm{BMI}$ - body mass index

$\mathrm{Cl}$ - Confidence Interval

DD - daily dose

$\mathrm{FEV}_{1}$ - Forced Expiratory Volume in 1 Second

Fostex ${ }^{\circledR}$ - is a brand name of BDP/F in Poland

GINA - Global Initiative for Asthma

HAT - histone acetyltransferase

HDAC - histone deacetylase

HFA - Hydro Fluoro Alkane

ICS - inhaled corticosteroids

LABA - long acting beta2 agonist

MART - maintenance and rescue therapy

MMAD - median mass aerodynamic diameter

OR - Odds Ratio

pMDI - pressurized metered-dose inhaler

\section{Declarations}

\section{Ethics approval and consent to participate}

Polish law does not require ethical approval and written informed consent for observational noninterventional study (information confirmed by the opinion of the local ethics committee).

\section{Consent for publication}

All authors provided written consent for the publication of this article. No personal patients data requiring consent for publication were used. 
All data are fully available without restriction on the request to Tomasz Debowski Chiesi Poland Sp. z o.o.

\section{Funding}

All study procedures, including patient-physician contacts, were managed by MMS Sp. z o.o. (Lodz, Poland), a contract research organization specializing in non-interventional observational studies. Total funding for the study and medical writing services was provided by Chiesi Poland Sp. z o.o. (Warsaw, Poland).

\section{Competing interests}

PK received personal fees for lectures from Adamed, Allergopharma, Almirall, Astra- Zeneca, GSK, HAL, Meda, Pfizer, Polfarmex, Stallergen, Teva, and LekAM and for lectures and advisory board activities from Boehringer Ingelheim, Celon Pharma, Chiesi, FAES, MSD, Novartis, and Polpharma. IK-L received personal fees for lectures from AstraZeneca, Chiesi, Nexter, and Novartis and for marketing projects activities from MMS. TD is a permanent employee of Chiesi Poland Sp. z o.o.

$\mathrm{CP}$ and $\mathrm{PL}$ declare no conflicts of interest

\section{Authors' contributions}

PK conceived the idea for the study and with other authors contributed to the design of the study. TD contributed to the design of the study, proposed the analysis according to smoking status and coordinated funding for the project. IK-L contributed to the design of the study, set the scope of the statistical analysis and wrote the first draft of the paper. CP wrote parts of the article devoted to the impact of smoking on health and asthma course. PL analysed and visualized the results. All authors thoroughly reviewed each draft and approved the final version of the manuscript.

\section{Acknowledgements}

The authors would like to acknowledge Mariusz Mianowany, MsC, for the statistical analysis of the data.

\section{Authors' information}

Izabela Kuprys-Lipinska is an expert in allergy and asthma diagnosis and management with more than 20 years of hands-on experience in managing asthma patients; she is an active lecturer, a invited speaker at asthma/allergy conferences, an academic at the Medical University of Lodz, a medical advisor and an author of numerous asthma/allergy clinical trials protocols and a devoted clinician; recently the main focus of her research is severe asthma, urticaria, specific allergen immunotherapy, hypereosynophilic syndrome and the application of biologicals in allergic diseases, member of the Main Board of Polish Allergology Society,

Cezary Palczynski is an expert in the fields of asthma, allergy, internal and occupational diseases; An active researcher and a teacher at the Medical University of Lodz with accolades for exceptional results in 
academia; author of numerous publications and guidelines in the field of allergy, asthma and occupational disease; both in clinical and research work he focuses on epidemiology and etiology of occupational allergic diseases and interaction between environment and health; a medical advisor and an invited speaker at allergy, asthma and public health conferences; a member of the Main Audit Commission of Polish Society of Allergology

Piotr Lacwik is a young active clinician and researcher at the Medical University of Lodz. In his clinical work, his core interests and activities include venom immunotherapy, in vivo provocation testing in allergy and asthma, as well as biological treatment of asthma and hypereosinophilic syndrome; An active academic and teacher at the Medical University of Lodz, his research is focused around treatment of anaphylaxis and practical aspects of self-injectable epinephrine, allergen immunotherapy and nasal provocation challenges; speaker at allergy conferences and workshops; A member and vice-chairman of the Section of Young Allergists of the Polish Society of Allergology

Piotr Kuna is a respected expert in asthma, a member of national and international advisory boards in asthma and allergy field, a country coordinator and principal investigator in many international clinical trials, which have a significant impact on guidelines for allergy and asthma management, an author of numerous asthma/allergy, an invited speaker at asthma/allergy national and international conferences, an academic team leader with a long-standing experience in scientific researches in asthma and allergy, a former President of the Polish Allergology Society,

Tomasz Dębowski, physician, Medical Director in Chiesi Poland Sp. z o.o., researcher and member of scientific societies. His core interest include assessment of real world data coming from non interventional studies in the field of obstructive lung diseases and neonatology.

\section{References}

1. https://ginasthma.org/wp-content/uploads/2019/06/GINA-2019-main-report-June-2019-wms.pdf Accessed from 20 Sept 2019

2. Higenbottam TW, Feyeraband C, Clark TJH. Cigarette smoking in asthma. Br J Dis Chest. 1980;74:27984.

3. Lange P, Parner J, Vestbo J, Schnohr P, Jensen G. A 15-year follow-up study of ventilatory function in adults with asthma. N Engl J Med. 1998;339:1194-200.

4. Althuis MD, Sexton M, Prybylski D. Cigarette smoking and asthma symptom severity among adult asthmatics. J Asthma. 2009;36:257-64.

5. Eisner MD, Yelin EH, Henke J, Shiboski SC, Blanc PD. Environmental tobacco smoke and adult asthma. The impact of changing exposure status on health outcomes. Am J Respir Crit Care Med. 1998;158:170-5.

6. Pedersen B, Dahl R, Karlstrom R, Peterson CG, Venge P. Eosinophil and neutrophil activity in asthma in a one-year trial with inhaled budesonide. The impact of smoking. Am J Respir Crit Care Med. 1996;153:1519-29.

Page 17/22 
7. Lazarus SC, Chinchilli VM, Rollings NJ, Boushey HA, Cherniack R, Craig TJ, et al. Smoking affects response to inhaled corticosteroids or leukotriene receptor antagonists in asthma. Am J Respir Crit Care Med. 2007;175:783-90.

8. Thomson NC, Chaudhuri R, Livingston E. Asthma and cigarette smoking. Eur Respir J. 2004;24:82233.

9. Kupryś-Lipińska I. Skuteczność montelukastu w ambulatoryjnym leczeniu astmy oskrzelowej u pacjentów powyżej 15. roku życia w warunkach codziennej praktyki lekarskiej (real life study). Pediatr Med Rodz. 2012;8:360-9.

10. Kuna P, Kupryś-Lipińska I, Dębowski T. Control of asthma in adults treated with beclometasone dipropionate and formoterol in extrafine particle formulation in a real-life setting in Poland: the CASPER noninterventional, observational trial. Pol Arch Med Wewn. 2015;125:731-40.

11. Travers J, Marsh S, Williams M, Weatherall M, Caldwell B, Shirtcliffe $P$, et al. External validity of randomised controlled trials in asthma: to whom do the results of the trials apply? Thorax. 2007;62:219-23.

12. Herland K, Akselsen JP, Skjonsberg OH, Bjermer L. How representative are clinical study patients with asthma or COPD for a larger "real life" population of patients with obstructive lung disease? Respir Med. 2005;99:11-9.

13. Laube BL, Janssens HM, de Jongh FH, Devadason SG, Dhand R, Diot $P$, et al. What the pulmonary specialist should know about the new inhalation therapies. Eur Respir J. 2011;37:1308-31.

14. Papi A, Paggiaro P, Nicolini G, Vignola AM, Fabbri LM, ICAT SE Study Group. Beclometasone/formoterol vs fluticasone/salmeterol inhaled combination in moderate to severe asthma. Allergy. 2007;62:1182-8.

15. Papi A, Paggiaro PL, Nicolini G, Vignola AM, Fabbri LM, Inhaled combination asthma treatment versus SSG. Beclometasone/formoterol versus budesonide/formoterol combination therapy in asthma. Eur Respir J. 2007;29:682-9.

16. World Medical Association. The declaration of Helsinki. http://www.wma.net/en/30publications/10policies/b3/. Accessed Jun 2016.

17. European Commission. Directive 2001/20/EC of the European parliament and of the council of 4 April 2001, Official Journal of the European Communities. https://ec.europa.eu/health/sites/health/files/files/eudralex/vol-1/dir_2001_20/dir_2001_20_en.pdf Accessed 20 Sept 2019

18. Polosa R, Thomson NC. Smoking and asthma: dangerous liaisons. Eur Respir J. 2013;41:716-26.

19. Gruzieva O, Merid SK, Melen E. An update on epigenetics and childhood respiratory diseases. Paediatr Respir Rev. 2014;15:348-54.

20. Kohli A, Garcia MA, Miller RL, Maher C, Humblet O, Hammond SK, et al. Secondhand smoke in combination with ambient air pollution exposure is associated with increasedx $\mathrm{CpG}$ methylation and decreased expression of IFN-gamma in T effector cells and Foxp3 in T regulatory cells in children. Clin Epigenetics. 2012;4:17. 
21. Invernizzi G, Ruprecht A, De marco C, Mazza R, Nicolini G, Boffi R. Inhaled steroid/tobacco smoke particle interactions: a new light on steroid resistance. Respir Res. 2009;10:48.

22. Eickelberg $\mathrm{O}$, Roth $\mathrm{M}$, Lorx R, Bruce V, Rudiger J, Johnson M, et al. Ligand-independent activation of the glucocorticoid receptor by $b_{2}$-adrenergic receptor agonists in primary human lung fibroblasts and vascular smooth muscle cells. J Biol Chem. 1999;274:1005-10.

23. Rüdiger JJ, Gencay M, Yang JQ, Bihl M, Tamm M, Roth M. Fast beneficial systemic anti-inflammatory effects of inhaled budesonide and formoterol on circulating lymphocytes in asthma. Respirology. 2013;18:840-7.

24. Profita M, Gagliardo R, Di giorgi R, Pompeo F, Gjomarkaj M, et al. Biochemical interaction between effects of beclomethasone dipropionate and salbutamol or formoterol in sputum cells from mild to moderate asthmatics. Allergy. 2005;60(3):323-9.

25. Roth $M$, Johnson PR, Rüdiger JJ, et al. Interaction between glucocorticoids and beta2 agonists on bronchial airway smooth muscle cells through synchronised cellular signalling. Lancet. 2002;360:1293-9.

26. Descalzi D, Folli C, Nicolini G, Riccio AM, Gamalero C, et al. Anti-proliferative and anti-remodelling effect of beclomethasone dipropionate, formoterol and salbutamol alone or in combination in primary human bronchial fibroblasts. Allergy. 2008;63(4):432-7.

27. Montalbano AM, Anzalone G, Albano GD, Sano CD, Gagliardo R. et al. Beclomethasone dipropionate and formoterol reduce oxidative/nitrosative stress generated by cigarette smoke extracts and IL-17A in human bronchial epithelial cells. Eur J Pharmacol. 2013;718(1-3):418-27.28. Clearie KL, McKinlay L, Williamson PA, Lipworth BJ. Fluticasone/Salmeterol combination confers benefits in people with asthma who smoke. Chest. 2012;141:330-8.

28. van Schayck OC, Haughney J, Aubier M, Selroos O, Ekstrom T, Ostinelli J, et al. Do asthmatic smokers benefit as much as non-smokers on budesonide/formoterol maintenance and reliever therapy? Results of an open label study. Respir Med. 2012;106:189-96.

29. Pilcher J, Patel M, Reddel HK, Pritchard A, Black P, Shaw D, et al. Effect of smoking status on the efficacy of the SMART regimen in high risk asthma. Respirology. 2016;21:858-66.

30. Brusselle G, Peche R, Van den Brande P, Verhulst A, Hollanders W, Bruhwyler J. Real-life effectiveness of extrafine beclometasone dipropionate/formoterol in adults with persistent asthma according to smoking status. Respir Med. 2012;106:811-9.

31. Marth K, Spinola M, Kisiel J, Woergetter C, Petrovic M, Pohl W. Treatment response according to small airway phenotypes: a real-life observational study. Ther Adv Respir Dis. 2016;10:200-10.

32. Roche N, Postma DS, Colice G, Burden A, Guilbert TW, Israel E, et al. Differential effects of inhaled corticosteroids in smokers/ex-smokers and nonsmokers with asthma. Am J Respir Crit Care Med. 2015;191:960-4.

33. Park HS, Yoon D, Lee HY, Ban GY, Wan Yau Ming S, Jie JLZ, et al. Real-life effectiveness of inhaler device switch from dry powder inhalers to pressurized metred-dose inhalers in patients with asthma treated with ICS/LABA. Respirology. 2019;24:972-9. 
34. Kuprys-Lipinska I, Kuna P. Impact of chronic obstructive pulmonary disease (COPD) on patient's life and his family. Pneumonol Alergol Pol. 2014;82:82-95.

35. Bednarek M, Gorecka D, Wielgomas J, Czajkowska-Malinowska M, Regula J, Mieszko-Filipczyk G, et al. Smokers with airway obstruction are more likely to quit smoking. Thorax. 2006;61:869-73.

36. Silva GE, Sherrill DL, Guerra S, Barbee RA. Asthma as a risk factor for COPD in a longitudinal study. Chest. 2004;126:59-65.

\section{Figures}

(a). Daily symptoms

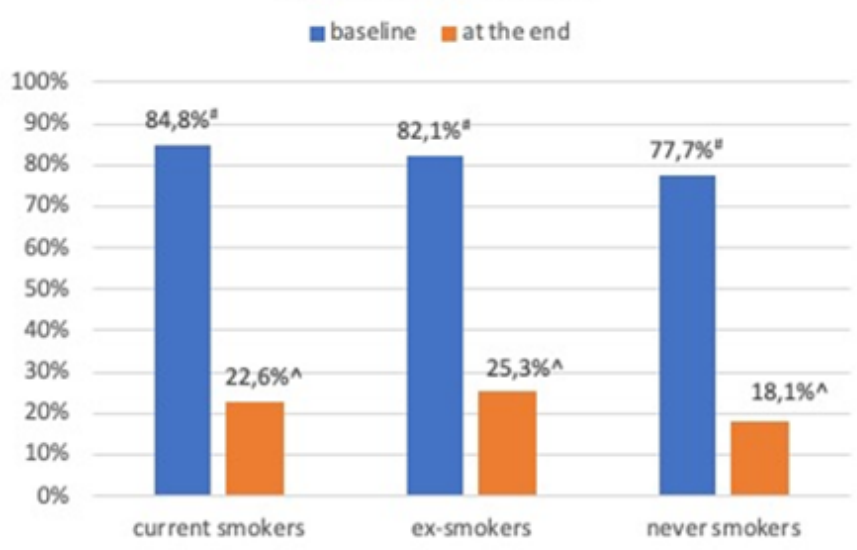

(c). Life activity limitation

mbaseline $m$ at the end

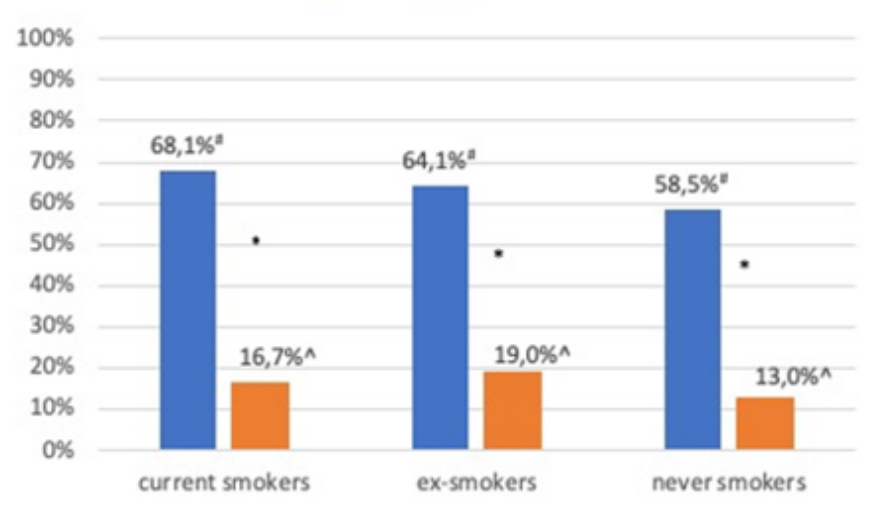

(b). Noctural symptoms

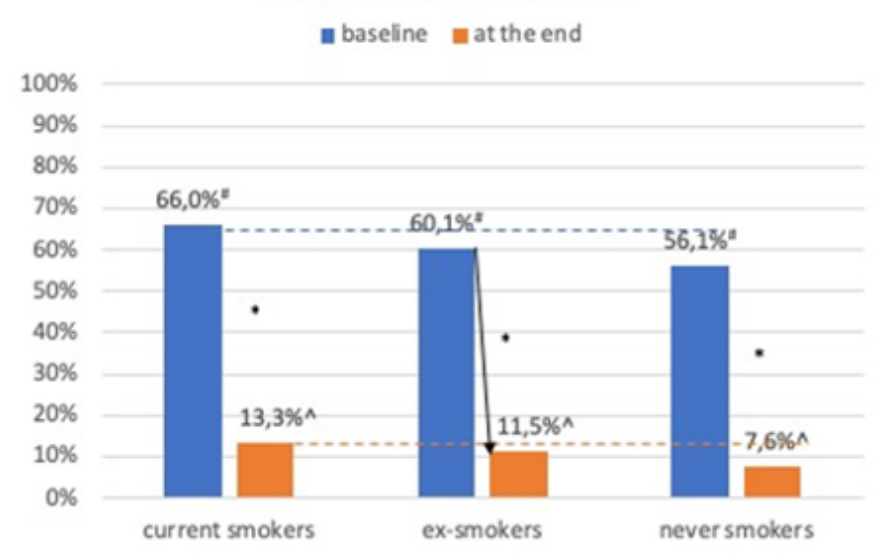

(d). Usage of rescue medication

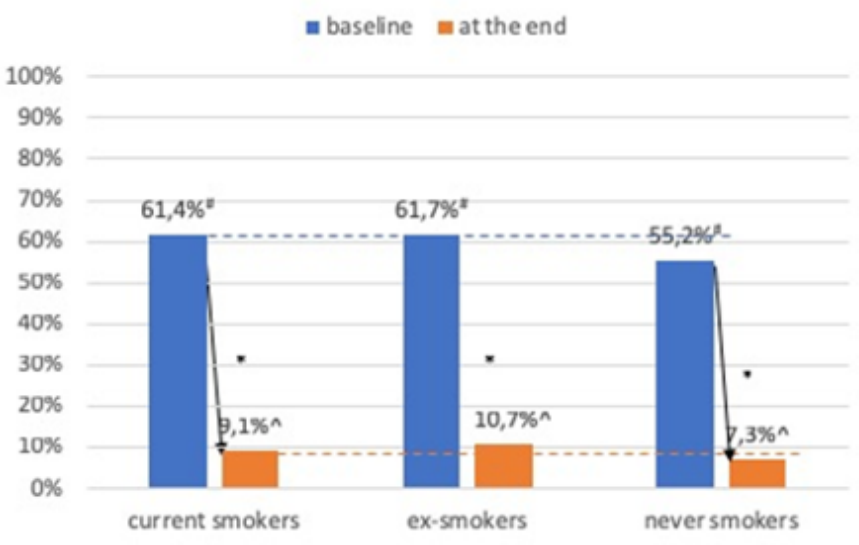

\section{Figure 1}

The percentage of symptomatic patients at baseline compared to the end of the 6-month observation period. Daily (a) and nocturnal asthma symptoms (b), life activity (c) and use of rescue medication (d) depending on the smoking status of the patients. *statistically significant difference within groups, \# and ${ }^{\wedge}$ statistically significant difference between groups 


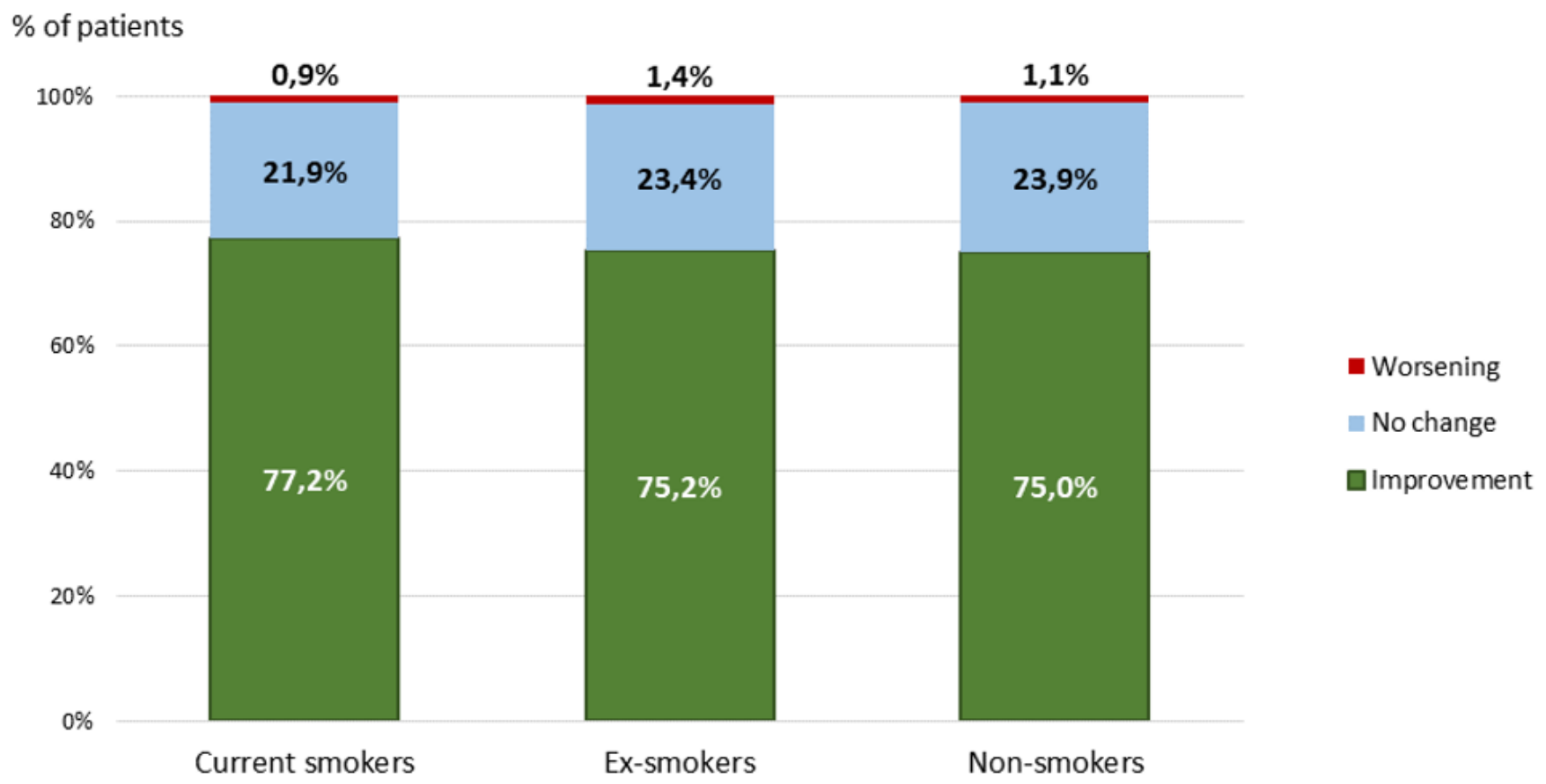

Figure 2

Improvement in asthma control at the end of 6-month observation vs baseline acc. to smoking status (NS).

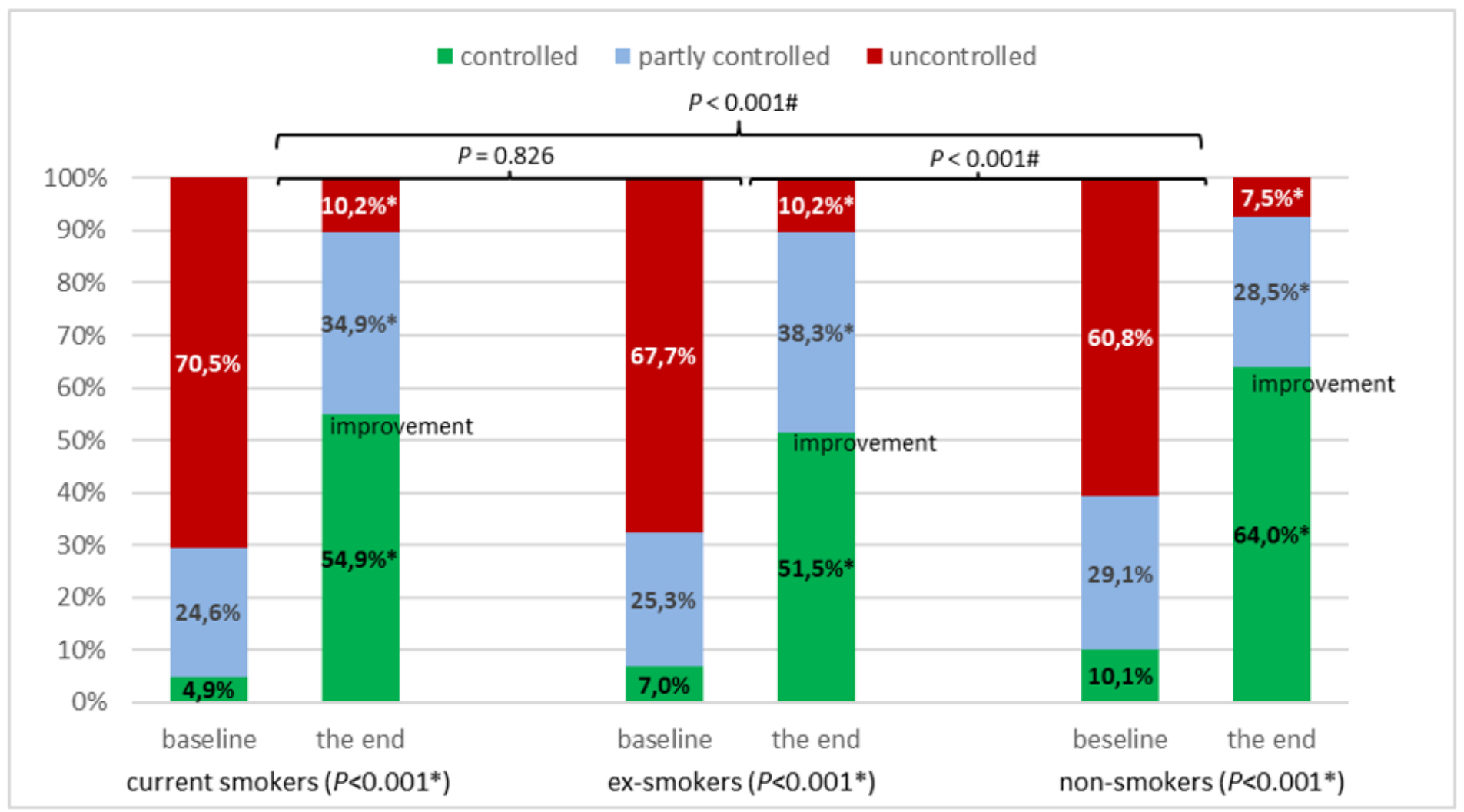




\section{Figure 3}

Percentages of patients with controlled asthma as defined by the GINA criteria over subsequent study periods acc. to smoking status. *statistically significant difference between baseline and the end of the study, \# statistically significant difference between non-smokers and current or ex-smokers, no significant difference was found between current smokers and ex-smokers. 